\title{
0 ARTIGO IV DA LEI HYPOTHECARIA
}

O Snr. Conselheiro Duarte d'Azevedo, cuja auctoridade na jurisprudencia nunca é demais encarecer, escreveu umas razões em causa hypothecaria debatida em o nosso Tribunal de appellação, as quaes, publicadas pela GazeTa JuridrCa, fasciculo do mez de Março deste anno tem corrido o mundo dos lettrados.

Lettrados que leiam as gazetas de leis ou jurisprudencia não ha muitos. Ha porém bom numero delles que não deixam de folhear as obras ao menos para saber que novidades tem-se aventado cá e lá, neste Estado ou nos Estados do Brazil.

Professor que sou da Faculdade de Direito, na qual sobresahio o Cons. Duarte d'Azevedo com tal clareza no ensinar e profundeza no conhecer, que as saudades do seu nome são mui vivas ainda, não posso de officio deixar correr sem humilde protesto uma theoria ensinada nas dictas razões, perigosa sob varios aspectos e de todo poncto inacceitavel.

Já daqui me humilho ante os collegas que na Faculdade ensinam o direito civil, que não é materia minha. Não póde porém o direito civil ser especiali- 
dade de ninguem, pelo muitissimo que a todos toca. Temos todos o dever de metter hombros a demolir, resistir, ou reconstituir, sempre que o progresso do direito reclame de nós uma daquellas forças.

'Presto, pois, meu contingente que ahi vai despretencioso.

$$
\text { ** } *
$$

1. Em pouco tentaremos compendiar a theoria do insigne jurisconsulto.

Disse: a) que o art. $4 .^{\circ} \S 6 .^{\circ}$ da Lei Hypothecaria está de todo obsoleto; o tempo já o aniquilou.

b) Que, embora o tempo não houvesse perimido aquella disposição da lei, todavia nulla não era a escriptura que omittira aquella declaração, porque o immovel, objecto do pacto hypothecario, fora adquirido no mesmo momento, e por isso seria absurdo crer que naquelle momento estivesse já gravado de hypotheca o que naquelle momento acontecia ao patrimonio do gravante.

$$
*^{*} *
$$

2. Chamamos toda attenção de nossos leitores para esse resumo que ahi fica feito. Estudemos cada um de per si.

$$
\text { ** }
$$

3. Caducou a disposição do art. $4 .^{\circ} \S 66^{\circ}$ ?

Nunca. Só caduca o que não se applica mais pelo desuso ou o que não se póde mais applicar pela repugnancia ou incompatibilidade. 
Não ha aqui logar ao desuso. Todos os dias se passam escripturas com taes declarações, bem que tambem todos os dias se passem outras sem ellas, já que é invencivel a ignorancia de muitissimos tabelliães.

Estudemos, pois, a repugnancia. Aqui é que gyra o eixo da argumentação do abalisado advogado, contra o qual temos honra em combater.

4. Façamos uma recordação brevissima dos diversos systemas de hypotheca:

Quanto á causa geradora ou fonte dondé promanam, as hypothecas se partem em convencionaes e legaes. Aquellas proveem da vontade dos contractantes; estas deduzem da lei sua existencia.

Quanto á causa, isto é sempre; mas quanto ao conterido e á publicidade é que as hypothecas tem variado entre nós com tres feições, bem caracteristicas, que vem a ser:

No regimen de I864, quanto ao conteúdo ellas eram especiaes, especialisadas e geraes; e quanto á publicidade dividiam-se em inscriptas ou manifestas e não inscriptas ou tacitas.

No regimen da lei de 1885 , quanto ao conteúdo tivemos a mesma triplice manifestação; mas quanto a publicidade, todas inscriptas. Acabou-se com as hypothecas tacitas e deu-se prazo de um anno para que as tacitas se inscrevessem, pena de caducarem. Reg. de I 886 , arts. 88 e 89.

No regimen de 1890 , que é o vigente, quanto ao conteúdo são especiaes ou especialisadas (quanto a terceiros) e quanto a publicidade devem ser todas inscriptas. Reg. 2 de Maio de 1890 , art. i 6 6. 
Deu-se prazo de um anno as inscriptas geraes para que se especialisassem afim de não caducarem. Reg. art. 397.

$$
*^{*} *
$$

5. E' força que transcrevamos verbo ad verbum alguns trechos das razões que confutamos para que mais claro resaltem as erroneas consequencias da argumentação assentada pelo Cons. D. de Azevedo:

«Havia hypothecas legaes validas "por terem sido inscriptas; porém mui«tas ou algumas não estavam especialisa«das, e difficil era portanto conhecerem-se «os immoveis sobre que recahiam, situa. * dos por ventura em outra comarca. «A declaração, pois, da parte do devedor «que se propuzesse a outorgar uma «hypotheca convencional, de que seus «bens se achavam livres de responsa«bilidades por hypotheca legal, era uma «garantia para o credor, e a falsidade «daquella declaração um acto de fraude, "que a lei considerou criminosa.

«Decorrido porém o anno desi"gnado para a especialisação das hypo«thecas legaes ainda não especialisadas, «as que ficaram valendo eram todas es"pecialisadas e inscriptas e nenhuma ra«zão mais tinha a exigencia da decla«ração irrposta pelo art. 4 § 6.»

$$
*^{*} *
$$

6. No dominio da lei de 1885 , como vimos, acabou-se com as hypothecas tacitas e mandou-se que 
todas se inscrevessem, pena de caducidade. Art. 86, do Reg. de i 886.

Ora, si todas as hypothecas legaes que até i 887 não se inscrevessem, estavam caducas, e só ficavam valendo as inscriptas, porque a lei de 85 e o Reg. de 86 exigiam que para validade das escripturas de hypothecas em geral (art. 87 2) houvesse a declaração do mutuario sobre a responsabilidade que onerasse seus bens com hypotheca legal?

$\mathrm{Si}$ a inscripção no Reg. Geral é a denunciação authentica e irrecusavel para todos, si a inscripção exclue qualquer allegação de ignorancia, para que exigir tão forte e energicamente tal declaração sob pena de nullidade da escriptura e crime do tabellião, caso a declaração não constasse?

E' que a lei não dispõe sci no interesse dos credores, mas dos devedores tambem, dos terceiros enr. geral e principalmente daquelles que constituem as varias classes privilegiadas, a cujo bereficio toda a culta legislação tem estatuido as hypothecas legaes.

Ninguem se lembrou no , tempo do Imperio' quando as leis se faziam a passo lento e ponderado, ninguem teve a má lembrança de dizer que, passado o anno de prazo constante no art. 89 do Reg. de 86, caducou a exigencia da declaração do art. 8, copiada ipsis verbis pelo art. $4 \S 6$ da novissima lei.

Entretanto se caducou aqui, não ha razão para que não tivesse caducado lá. Mas, penetrando um pouco mais fundo no estudo da hypotheca, acharemos o porque lá não caducara no Imperio e porque tambem aqui na Republica de modo algum caducou aquella exigencia, em que pez ao egregio advogado que temos á nossa frente.

$$
* *
$$


7. Sabemos que o estudo que vamos fazendo é por natureza arido, pouco attrahente. E' preciso, porém, que saiba a mocidade que nos lê que foi sempre difficil a carreira das lettras juridicas. Quem se mette a isto é que tem energia de vontade e tenacidade no aprender. Labor omnia vincit arduus.

Corrido o anno de prazo dado pelo art. 89 do Reg. de 86 , as hypothecas legaes que não estivessem inscriptas deixavam de ser hypothecas para os terceiros. Mas o direito civil nunca pára e nunca parou entre nós, nem ainda sob este regimen em que tudo quer parar. De modo que apezar da execução da lei de 85 com seu Reg. de 86, as relações do direito civil continuaram as mesmas, a saber as hypothecas legaes nas suas variadas especies foram nascendo e renascendo, sempre validas entre os vinculados por ella quer tacilas quer inscriptas, mas só validas para com terceiros depois da inscripção.

A pena de caducidade, portanto, imposta no final do art. 89 do Reg. de 86, só fere e alcança as relações de terceiros, porque os interessados no vinculo hypothecario, esses não dependem da inscripção para que valha em seu pról ou em seu damno as hypothecas legaes a que estão adstrictos.

$$
*^{*} *
$$

8. Applicando os mesmos principios ou a mesma regra ás novissimas disposições da lei de 9o, chegaremos ás mesmas conclusões. E é o que entramos a fazer.

Pelo systema de 85 acabou-se com as hypothecas tacitas e prescreveu-se que todas fossem inscriptas para valerem contra terceiros. O systema de 90 deu um passo avante no sentido de discriminar e esclarecer os 
deveres e direitos que estão implantados ás hypothecas legaes. Deu prazo de um anno ás inscriptas para que se especialisassem e determinou que as novas todas se especialisassem para assim serem inscriptas.

Vejam bem nossos leitores que o que fez a lei de 85 das tacitas para as inscriptas, fez a lei de 90 das inscriptas para as especialisadas.

E notem com toda attenção que todas essas disposições só concernem ás relações de terceiros, porque as relações dos vinculados em nada se alterou nem por um nem por outro systema.

$$
*^{*} *
$$

9. O primeiro erro portanto da theoria sustentada pelo Cons. Duarte de Azevedo é este - acreditar que a disposição energica do art. $4 \S 6$ só diz respeito a terceiros. Eis ahi a prima causa malorum.

Aquella exigencia que como dissemos é a consagrada no art. 8 da lei de 85 , repetida agora no art. $4 \S 6$, aquella exigencia, si é algum favor especial, o é para as classes privilegiadas, dado este nome a todo aquelle em pról de quem foram creadas as hypothecas legaes. O Cons. Duarte de Azevedo parece que só encarou a dicta exigencia como favor aos mutuantes, que pretendessem hypothecas convencionaes de pessoas gravadas de hypotheca legal. Desçamos á analyse de alguns trechos de suas razões.

$$
\text { A }
$$

«Havia hypothecas legaes validas "por terem sido inscriptas; porém muitas «ou algumas não estavam especialisadas «e difficil era portanto conhecerem-se os «immoveis sobre que recahiam, situados «por ventura em outra comarca.» 
Não é por terem sido inscriptas que as hypothecas de 85 eram validas. A inscripção é a denunciação authentica, legal e irrecusavel. Ninguem se póde defender allegando ignorancia, quando ha no Registro Geral a inscripção feita.

A inscripção póde ser viciada e nulla, como nulla póde ser a hypotheca inscripta. A inscripção não dá sanidade á hypotheca viciada, como a falta de inscripção não deprime a substancia da hypotheca boa.

Para sua validade intrinseca, pois, ella é inteiramente independente da inscripção. Sem esta, eis o caso, os terceiros não ficam affectados pelo vinculo hypothecario. Mas os que intervieram na constituição da hypotheca ou se enlaçaram nos vinculos della, esses não são terceiros, esses são obrigados, quer haja, quer não haja inscripção.

Outro poncto: a hypotheca legal simplesmente inscripta no systema de 85 , irradiava-se não só aos bens do responsavel existentes ao tempo, como alcançava os que elle fosse adquirindo durante a constancia da hypotheca.

Não era impossivel, só era ás vezes difficil, conhecer si estavam ou não os bens de Pedro gravados. Sendo o registro feito na comarca da situação, alli devia-se encontrar a inscripção. Si esta faltasse, houvesse ou não houvesse hypotheca legal, ella não feria nem alcançava aos extranhos, isto é, aos terceiros.

$$
\text { *** }
$$

10 «A declaração, pois, da parte do «devedor, que se propuzesse a outorgar «uma hypotheca convencional, de que "seus bens se achavam livres de res"ponsabilidade por hypotheca legal, era «uma garantia para o credor... 
Ha aqui um grave engano. $O$ preceito da lei não é que o mutuario faça constar simplesmente que seus bens estão livres de hypotheca legal, mas que o mutuario faça constar si sobre seus bens pesa tal gravame e qual elle é, caso exista. E' claro, é evidente que, si houver responsabilidade, o mutuario deve narrar em que consiste, para assim a verdade ser conhecida por inteiro, pois o mutuario mentiroso incorre em crime.

Nem a existencia desse gravame obsta á hypotheca convencional. O que sim é que, o mutuante que fez hypotheca convencional, não póde jámais allegar ignorancia nem invocar para si a posição de terceiro diante dessa hypotheca legal constante na escriptura de seu contracto por obrigação restricta da lei.

Não é, portanto, uma garantia tão só para o mutuante que contractou hypotheca convencional, mas é garantia geral para todos, credores e devedores e terceiros em geral, porque si ha caso em que a verdade jámais prejudicou é este.

Continuemos a analyse.

$$
\text { ** }
$$

11 «Decorrido, porém, o anno de "prazo para a especialisação das hypo«thecas legaes ainda não especialisadas, as "que ficaram valendo eram todas especiali«sadas e inscriptas, e nenhuma razão mais «tinha a exigencia da declaração imposta "pelo art. 4 §6, do Dec. de I 9 de Janeiro. «O decreto não comprehendeu essa exi"gencia entre as disposições transitorias, "porém, ella desappareceu pela natureza «das coisas.» 
Aqui temos a mais grave das affirmações erradas, que escaparam ao provecto jurisconsulto.

As hypothecas legaes simplesmente inscriptas (como era o regimen de 85) valiam contra todos. A lei de 90 marcou um prazo fatal de um anno para que se especialisassem e assim depois se inscrevessem, pena de não mais valerem contra terceiros.

Diz o nosso antagonista que no correr desse anno de prazo teve vigencia a disposição do art. $4, \S 6$. Depois caducou pela natureza das coisas, como quem diz: Passado o anno de prazo, repugna ao direito vigente e aos mais preceitos da lei hypothecaria que continue em vigor aquella disposição.

E' o maximo dos enganos!

O Snr. Cons. Duarte de Azevedo ha de bater em consequencias erradas desque assentou falsas premissas. S. Exc. assentou comsigo que a especialisação obrigada pela novissima lei foi um mandamento em pról dos credores de hypothecas convencionaes, e, pela exposição de sua falsa theoria se vê que não tira os olhos de sobre elles, como o facto que attrahe sua melhor attenção. E assim discute que as hypothecas legaes que se não especialisaram no decurso de um anno, não mais valeriam, e que ficam valendo só as que se responsabilisaram e inscreveram.

A verdade é que todas as hypothecas legaes, constituidas validamente, quer inscriptas quer não, quer especialisadas quer não, são validas, tem vigor juridico, vigor que não é intrinsecamente modificado pela inscripção. No correr do anno de prazo, diz o notavel jurisconsulto, já que ellas valiam sem especialisação, era preciso avisar os credores convencionaes e dahi a necessidade de declarar nas escripturas a existencia do gravame legal. 
Passado o anno, só tem vigor as especialisadas e inscriptas, logo a disposição energica do art. $4:^{\circ}$, $\S 6 .^{\circ}$ não tem mais razão de ser.....

$\mathrm{O}$ argumeuto não precisa ninguem arremetter contra elle para o derribar. Elle cae de si mesmo.

Si ellas eram inscriptas simplesmente em termos geraes, eram conhecidas de todos, porque a inscripção é a denunciação solenne que a todos obriga.

Si ellas são especialisadas e inscriptas tambem são conhecidas de todos, porque ninguem póde allegar ignorancia ante a certeza da inscripção.

Onde, pois, o criterio para se argumentar da vigencia da lei lá para a caducidade aqui?

E' claro que não ha repugnancia, não ha incompatibilidade alguma, que obrigue á caducidade.

O que ahi perturba o raciocinio de tão preclaro talento é o preconceito de que a lei cogitou neste passo dos interesses do credor convencional. Não ha tal.

O não valer contra terceiros ou a respeito de terceiros não é o mesmo que não valer.

$$
*^{*} *
$$

12. A lei determinou que as hypothecas legaes todas se especialisassem e se inscrevessem. Este é o preceito; preceito a todos os interessados, preceito aos escrivães, aos tabelliães, testamenteiros, juizes, etc., como se póde ver nos capitulos especiaes a cada caso de hypotheca legal.

Apezar de tantas e taes admoestações, ordens e ameaças, será verdade que as hypothecas legaes se especialisam e inscrevem?! E' vergonha dizel-o, mas 
é a verdade: talvez a decima parte dellas é que está a rigor da lei. Tudo o mais, anda na maior e mais descurada relaxação!

O Instituto dos Advogados de S. Paulo já discutiu e votou uma representação ao Congresso, solicitando que cogitasse por uma refórma na lei hypothecaria do desmazelo que grassa neste assumpto com detrimento dos interesses que a lei tanto quiz acautelar com a hypotheca legal.

Ora, quem lê as razões do Cons. Duarte de Azevedo parece que naturalmente conclue que tudo que não estiver inscripto está para nada.

Não e nunca. Si pelo nosso calculo $\frac{9}{10}$ das hypothecas legaes não se tem especialisado e portanto não se tem inscripto, é certo todavia que no seio desta lei viciosa e disparatada como é, feita por tres espadas, dois generaes e um generalissimo, encontram-se contrapesos a essa calamidade. $O$ jogo ou manobra do rodame e correame da machina não é facil, mas não podemos em menoscabo dos tres gereraes que a fizeram de um golpe, não podemos dizer que ella largou ao Deus-dará todos os interesses, cujos vinculos não constam do registro hypothecario.

$$
*^{*} *
$$

13. Faz muito ao nosso proposito reverter contra o Cons. D. d'Azevedo o seu principal argumento:-

Não valem as hypothecas desde que não estão especialisadas e inscriptas. Logo não ha mais logar a exigencia do art. $4 .^{\circ} \S 6 .^{\circ}$

Retorquimos:--Nem todas as hypothecas legaes se especialisam e inscrevem. Muito pelo contrario, pouquissimas é que se mettem no caminho e rigor 
da lei. Logo é mais que nunca necessario que haja a declaração do mutuario afim de não cahirem em erro os que negociam com sujeitos gravados de hypotheca legal.

14. A lei fulminou a pena de nullidade contra as escripturas omissas ou silenciosas relativamente á declaração das hypothecas legaes que oneram o mutuario, e fulminou a pena de estellionato sobre o mutuario mentiroso. Estas penas severissimas precisam de razão de ser.

Si tivessem sido méra invenção dos auctores da novissima lei, não nos devia fazer móssa; que obra de tres generaes não é maravilha que saia golpeada de incongruencias e novidades. Mas já a lei de 85, como atraz citarnos, estatuio essas penas: é força que busquemos e achemos a razão dellas.

$$
*^{*} *
$$

15. A lei admoesta a uns, pede a outros, ordena a muitos que cuidem de inscrever as hypothecas legaes e leva o zelo a ameaçar e punir. Entretanto, o homem é o homem; e com suas fraquezas e desidias conta sempre deve sempre contar o legislador.

Assim o fez. Certo de que, apezar de cercadas as hypothecas de todas as providencias creadas em ordem ao registro, tal registro em muitos casos se não faria, como em verdade se não faz, ordenou a lei um freio contra os devedores ou obrigados remissos ou relapsos e esse freio é a exigencia muito racionavel do $\operatorname{art.} 4 .^{\circ} \S 6 .^{\circ}$

Ou faz o mutuario a declaração e é valida a escriptura hypothecaria que outorga, ou não a faz e então é nulla de pleno direito. No primeiro caso, va- 
lida a escriptura de hypotheca convencional, como nella ficou manifestada a responsabilidade das hypothecas leyaes, o credor convencional deixa de ser ter-. ceiro para ser interessado ou vinculado nas malhas da obrigação que lhe era dantes extranha, não podendo allegar seus direitos hypothecarios com preferencia aos da mulher casada, menores, pupillos, ou quem quer que no caso seja o titular da hypotheca legal.

$\mathrm{Ou}$ então, si na escriptura se fez silencio quanto ás responsabilidades do mutuario por hypothecas legaes, neste caso nada soffre, nem de leve é melindrado o direito dos credores privilegiados (chamamos taes os de hyp. legal), porque tal escriptura de hypotheca convencional é NULLA DE PLENo DIREITO.

Eis porque afoitamente affirmamos, sem sombra de receio algum, que, si cogitou a lei com tal medida do bem particular de alguem, foi do bem das nove classes privilegiadas, em cujo pról se crearam as hypothecas legaes, a saber: a mulher casada, o filho menor, o pupillo, o interdicto, a fazenda publica, a corporação de mão morta, o offendido, o co-herdeiro e o credor com sentença exequivel.

De maneira que, estudada a esta luz irrecusavel, a saber o interesse dessas classes particularmente acobertadas pela lei, a providencia do art. $4 .^{\circ}$ é salutarissima, apezar de ser um tanto complicado o rodame da machina, cujas entrosas não calham bem, e em cuja superficie notam-se galhas e asperezas quinas vivas, revelando-se em tudo a obra que é, mal chanfrada por tres espadas de general ou melhor por uma espada de tres generaes.

16. Mas, perguntamos agora á nossa consciencia, mas não será uma forçada illação concluir da exigencia do art. $4 .^{\circ} \S 6 .^{\circ}$, concluir desse grave pre- 
ceito e de sua gravissima sancção, que o credor convencional, sciente da legal obrigação do mutuario, não é mais terceiro?

Cremos que a illação é a mais natural do mundo e a unica consentanea com a natureza das relações creadas pela novissima lei.

$$
* *
$$

1\%. QUEM SÃo TERCEIROS?

Terceiros não é facil dizer numa palavra quem são. A lei vigente no art. 64 disse-o numa palavra; mas, si por favor não disse errado, todavia disse com muita imperfeição.

«Consideram-se terceiros, no sentido «da lei, todos os que não forem partes «no contracto ou seus herdeiros.»

A palavra contracto é tomada aqui no sentido latissimo. Contracto é o facto ou o conjuncto de factos, uns voluntarios, outros não, de que resultou a hypotheca legal.

E si tractarmos dá hypotheca convencional, então podemos acceitar a explicação de terceiros dada nesse art. 64 .

No direito francez varios arts. falam em terceiro; e, segundo é a materia de que se tracta, assim toma diversos matizes a significação desse vocabulo. Vide Dalloz, verbo Tiers, n. I, 2 e 3 .

«O terceiro propriamente falando, «é o que não foi parte nem represen«tado pelas partes em um acto, con«venção ou julgamento ... Ha o ter«ceiro inteiramente extranho ás partes e 
«á convenção, que os Doctores chamam "penitus extraneus; e ha o terceiro que, "posto que extranho á convenção ou «julgamento que se lhe oppõe, é entre«tanto sob outros aspectos ou relações «O subrogado de uma das partes. Obra «cit. n. 2 ».

Não é tudo: o sentido da palavra terceiro nem sempre tem a mesma latitude. E passa a exemplificar em arts. do Cod. Civil e leis francezas).

E continua: «A qualidade de terceiro «é pois puramente relativa: tal indi«viduo póde ser terceiro sob certas «relações e não o ser sob certas outras. "Vê-se dahi que é impossivel determi«nar de modo absoluto quaes pessoas «são e quaes não são terceiros, devendo«se interpretar sempre o sentido d'essa «palavra segundo a disposição especial «que se trata de applicar. Ob. cit. n. 3.

$$
\text { ** }
$$

18. A lei de 64 nada adianta quanto á explicação de que sejam terceiros. O Reg. de 65 no art. 67 diz perfeitamente as palavras que lemos no art. 64 da novissima lei.

Ora, as relações do direito hypothecario em materias de hypothecas legaes eram muito outras do que são hoje. Basta dizer que as hypothecas legaes da mulher casada, do menor e do interdicto valiam contra todos ainda sem inscripção. Entretarto a palavra terceiro apparece não só no art. I 23 , como no $\S$ I 2 do art. $3 .^{\circ}$ do Reg. de 65 e muito ha que dizer sobre 
sua significação, principalmente quando vemos a seccura com que o art. 64 do Reg. actual reproduzio ipsis verbis o dizer da lei antiga, sendo já outros os principios dominantes.

$$
*^{*} *
$$

19. Afoitamo-nos pois a affirmar que terceiros só são aquelles que tem direito de allegar ignorancia das hypothecas legaes, porque não conheciam nem pela inscripção, que é a denunciação universal, nem por outro modo legal, authentico e obrigatorio, qual o do art. 4 § 6 da lei vigente.

Ampliando a definição de Dalloz podemos dizer que terceiro é o que não foi parte nem representado pelas partes em algum acto, convenção ou julgamento, nem se vinculou posteriormente ás relações irradiadas de um facto ou acto gerador de hypotheca.

$$
*^{*} *
$$

20. Desçamos um pouco ao terreno chão dos factos.

O marido que tem seus bens gravados pela hypotheca legal oriunda do dote de sua mulher, e que, dando hypotheca convencional desses bens já gravados, mas não especialisados nern inscriptos, narra na escriptura do contracto, segundo manda 0 art. $4 \S 6$, que sobre seus bens pesam as responsabilidades legaes oriundas do dote, que garantia dá a seu credor convencional?

Só dá as que se compadecem com a existencia e validade da hypotheca legal. Nem tal credor, sciente do gravame dos bens e da situação de seu devedor, póde allegar jámais que sua hypotheca convencional 
prefere á da mulher dotada, pois elle não é terceiro no rigor dos principios, visto que não é inteiramente extranho ás obrigações hypothecarias ou antes aos vinculos que já prendiam os bens que the foram dados em garantia. Si pois o fito da inscripção não $e$ dar valor ás hypothecas, mas fazel-as conhecer (e isto não no interesse do credor ou devedor, mas no interesse do bem de todos), é evidente que não se póde acobertar sob a capa de terceiro quem soube do caso por miudo, de modo authentico, legal, innegavel, porque a lei obriga ás partes e ao tabellião que declarem na escriptura que se vai fazer quaes as responsabilidades por hypothecas legaes que pesam sobre os bens do mutliario.

$\mathrm{Si}$, porém, o credor ignorava a situação real do mutuario, e este nada fez constar na escriptura nem o tabellião o interpellou, é claro que elle ficou em perfeita ignorancia em relação ás hypothecas legaes, que haja por ventura no caso; elle ficou no papel de terceiro.

Nesta conjunctura, porém, em vez de elle se achar primeiro credor sobre os bens do marido, a hypotheca convencional é nulla de pleno direito, e quem se acha incolume, quem se acha ainda em primeiro logar é a mulher dotada, apezar de não estar inscripta sua hypotheca.

Eis a razão da grave pena que a lei fulminou ás escripturas omissas;- SALVAR OS DIREITOS DAS CLASSES PRIVILEGIADAS.

$$
*^{*} *
$$

21. Outro facto. Morta a mãe que deixou filhos menores, nasceu desse facto a hypotheca legal desses filhos contra os bens paternos. 
Sem o inventario e partilha não se póde determinar o valor das quotas hereditarias, e sem isto a especialisação não se póde fazer e portanto não póde o pai, por mais que seja diligente, inscrever a hypotheca legal de seus filhos.

O facto de estar em communhão com seus filhos não inhibe o pae de hypothecar seus bens, desde que ponha os pontos nos iis e não falte aos deveres paternaes nem aos deveres civicos com o credor mutuante.

Para não faltar a nenhum ponto de sua probidade, ha de declarar que o immovel que hypotheca é só seu em parte ideial e que, de mais a mais, não tendo ainda havido partilha, unico modo de attribuir a cada um parte certa, elle não teve tempo de especialisar a hypotheca dos filhos, os quaes, não obstante isso, são seus credores de hypotheca legal, o que vale o mesmo que dizer: Todos os immoveis (na parte que pertence ao pai) são hypothecados aos filhos em garantia dos bens maternos, de modo que qualquer hypotheca convencional feita nesses termos está ex-vı legis posposta á legal dos filhos. Eis como, sem tolher ao pai a administração e meneio dos bens communs, prestou a lei a maneira lisa e chã de salvaguardar o direito dos credores convencionaes.

$$
*^{*} *
$$

22. Cessemos aqui. A doutrina do Cons. Duarte de Azevedo é improcedente de todo ponto; anarchisa o direito já tão trabalhado pelas espadas dos generaes, pela puerilidade dos legisladores, pela ignorancia crescente dos juizes e por um sem numero de tropeços, que fazem solavancar em seu caminho o carro da jurisprudencia. 
Está em pleno vigor o art. $4 \S 6$.

$\mathrm{Ai}$ de nossa sociedade, ai dos interesses das classes privilegiadas pelas hypothecas legaes, si houver juizes que sanccionem com suas sentenças a opinião perniciosa que.a auctoridade do notavel jurista ainda torna mais clamorosa!!

\section{SEGUNDA PARTE}

23. Muito longe vai isto. Mas precisamos de encarecer a gravidade dos erros, consagrados nas razões que confutamos. Eis porque os leitores relevarão mais algumas linhas como formando uma segunda parte. O eximio professor de direito, ponderando sobre a circumstancia aliás communissima de se haver na mesma escriptura de acquisição estipulado o pacto hypothecario, permanecendo o immovel ora adquirido em segurança do preço fiado, affirma estas palavras que forçam a admiração:

«Nestas circumstancias, como seria «possivel que os compradores estivessem «onerados de hypotheca legal sobre os «bens que adquiriram nesse momento «mesmo? Seria uma necedade suppor «que os bens comprados se achavam «antes ou no instante da compra, su«jeitos á hypotheca dos compradores».

Não é necedade de modo algum. O Snr. Cons. Duarte de Azevedo, esperamol-o com todo empenho da mais cordial sympathia, ha de ter vida para ajudar outra geração a restaurar tudo isto que vai aos boléos, quando melhores dias Deus dér a este paiz unificado sob o sceptro.

Iamos dizendo que, apezar dos desconcertos que enxameam na refórma hypothecaria, não é necedade acreditar que o adquirente do immovel no mesmo acto 
de o adquirir já o tinha gravado de hypotheca legal. Não é necedade.

A hypotheca legal em regra onera tODOS OS BENS do responsavel. A especialisação é que vem encerrar a responsabilidade dentro de certos e determinados limites, gravando certos e determinados bens. Desta arte, acontecendo qualquer desses factos geradores de hypotheca leyal, por exemplo a morte da mulher casada, seus filhos desde esse momento tem sobre os bens paternos, não obstante a communhão, hypotheca legal e geral, que só pela especialisação se restringe. O mesmo se dá ao momento em que o tutor subscreve o termo da tutela. E assim de ceteris.

Ora, imaginemos que um determinado sujeito, exemplo o cliente em cujo favor o Snr. Cons. Duarte de Azevedo sustentou tão extranha theoria, imaginemos que no momento de adquirir a fazenda que no mesmo acto hypothecou, elle tinha subscripto um termo de tutela ou curatela e não havia especialisado a legal hypotheca a favor do menor ou do interdicto. Como é indubitavel, absolutamente indubitavel, que primeiro elle adquiriu a fazenda e depois é que hypothecou ao vendedor, embora tudo dentro da mesma escriptura e dentro do mesmo quarto d'hora, é por egual incontestavel que ao momento de entrar dita fazenda para seu patrimonio, ella ficou gravada pela hypotheca legal, porque esta abarca todos os bens e portanto compreendeu tambem a acquisição daquelle momento. Hypothecada a fazenda ao vendedor, essa hypotheca convencional JÁ É SEGUNDA, porque antes della está a LEGAL. Devia, pois, o devedor declarar e devia o tabellião fazer constar os encargos que sobre seus bens pesavam ex-vi legis.

Tal declaração, ao mesmo tempo que salvaguarda os interesses do menor ou interdicto, esclarece ao 
mutuante a situação do devedor e o põe em segunda linha como credor hypothecario, porque constando-lhe de modo authentico a hypotheca legal anterior, nunca póde a convencional preferir áquella, ainda que a convencional se inscreva na mesma hora e a legal nunca se inscreva, pois a inscripção só é de mister para terceiros, e em nosso caso não ha terceiros, porque o menor ou o interdicto, o vendedor e o comprador obrigado, em suas reciprocas relações acham-se de tal modo vinculados, que nenhum pode invocar o papel ou posição de terceiro ante os outros dois.

\section{TERCEIRA PARTE}

24. Diziamos ao numero antecedente que em regra a hypotheca legal grava todos os immoveis do responsavel e que o processo da especialisação é que circumscreve a orbita do gravame legal a certos e determinados bens.

Accentuemos isto, porque tal ponto, fóra de possivel duvida para quem lê attentamente a materia, não teve a adequada intelligencia em certo tribunal deste paiz.

Queremos falar do caso de Maceió, constante á fls. 305 e seguintes do fasciculo de Julho deste anno da Revista de Jurisprudencia do Rio de Janeiro.

Faz-se longa demais esta dissertação si trouxermos á luz a integra dos dizeres de pay. 307 em diante.

Aventa-se ali o caso de haver a escriptura de hypotheca convencional declarado expressamente que os bens então hypothecados não estavam sujeitos a quaesquer responsabilidades por hypotheca legal. 
O Accordam pondera que a exigencia do art. $4 .^{\circ}$ $\S 60^{\circ}$ é acautelar os direitos dos entes privilegiados a cujo beneficio foram instituidas as hypothecas legaes. E não pondera mal. O disparate vem depois, e transparece quando diz que por affirmár o mutuario a isenção de gravame nos bens que ora offerece em hypotheca, ipso facto affirma tambem que todos seus bens estão isentos.

25. Antes de tudo é original e curioso que um tribunal superior esteja a eludir ou burlar a prescripção legal. Preceito é preceito; conselho é conselho; nullidade é nullidade. A lei e o reg. actual, como a lei e o reg. de 85 , fulminam a nullidade absoluta, de pleno direito, aos contractos omissos. A lei manda que se desvende a situação do responsavel sob o as. pecto das hypothecas legaes. E esse preceito, cuja energica disposição não póde ser mais accentuada, requer que se deçlare não só a situação do responsavel considerada quanto aos bens que ora hypotheca, mas a sua situação quanto a todos os bens.

A escriptura, pois, que fala e tracta só dos bens que são objecto de uma hypotheca convencional, é falha e falsa e nulla de pleno direito, porque não satisfaz á disposição legal.

26. Dando agora de barato que tal declaração relativa aos bens ora gravados convencionalmente satisfaça ao intuito legal, fica de pé outro erro de crassitude pouco commum: é o affirmar o Accordam que as hypothecas legaes sempre abrangem todos os immoveis do patrimonio do responsavel!!

E' aspero dizel-o: mas ha casos em que uma exclamação como esta deixa de ser atrevimento por ser verdade evidentissima: os magistrados nem leram a lei hypothecaria!! 
Si é verdade que ordinariamente a hypotheca legal desde o momento de sua existencia até ser especialisada grava todos os immoveis do responsavel, é tambem certo que a hypotheca legal póde já nascer onerando tão só certos e determinados bens. Taes são estes dois casos:

a) quando na escriptura dotal foram mencionados os bens seguradores do dote, a hypotheca da mulher dotada só poisa nos bens nomeados, isentos todos os mais ;

b) a hypotheca legal do co-herdeiro só grava o immovel em que elle tinha condominio e que foi addicto ao co-herdeiro reponente: todos os mais bens do reponente são immunes dos vinculos dessa legal hypotheca. VIDE arts. i64 e segs., e 200 do Reg. hypothecario.

27. Em os termos acima expostos, é sophistica a argumentação do Tribunal de Maceió, a qual dá este syllogismo: Si ha no caso hypotheca legal, ella abarca todos os bens do obrigado. Ora, ha um be:n do obrigado Pedro que sabemos livre e isento de hypotheca legal. Logo todos os bens de Pedro estão livres de hypotheca legal.

A esse syllogismo responde peremptorio est'outro: As hypothecas legaes nem sempre gravam todos os bens do responsavel ou obrigado.

Ora eu tenho certeza que tal propriedade de Pedro não está gravada com hypotheca legal. Logo fico em duvida si os mais bens delle se acham ou não se acham isentos de hypotheca legal.

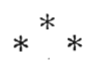




\section{$-193-$}

28. Sinão vejamos :

Supponhamos que o mutuario Pedro, ao fazer da hypotheca convencional, faz a declaração nos termos que relata o Tribunal de Maceió.

Suponhamos ainda que Pedro é adjudicatario de um predio commum e deve reposição a seus co-herdeiros. Não é esse predio commum que elle quer hypothecar, mas outro.

A declaração que elle exarou na escriptura é mentirosa; pois si é verdade que sobre o predio que elle ora hypotheca não pesa gravame legal, é tambem verdade que ha uma propriedade sua (o predio adjudicado) gravado de hypotheca legal.

Entretanto isso ninguem deduz de sua declaração omissa ou manca.

$\mathrm{O}$ que a lei quer e manda com absoluto imperio é que declare a escriptura si sobre os bens do mutuario pesa responsabilidade derivada de hypotheca legal.

Nịnguem põe duvida em que a declaração no caso de Maceió contém alguma verdade; mas a verdade no sęu perfeito conceito e para o caso que nos occupa nùca será a verdade, si algo de mentira ou falsidade se intrometter no seu conteúdo.

$\mathrm{Faz}$ ao ponto o aphorismo da moral: Bonum ex integra causa: maeum ex quocunque defectu. Si no dicto ou affirmação do mutuario ha alguma coisa do cumprimento do dever que a lei impõe, ha de mistura o vicio de occultar a situação dos outros bens, porque, como já vimos, o que quer e exige a lei é que conste a situação do mutuario relativa a todos os seus bens.

$$
\text { ** } *
$$

29. O que ficou dito ao caso da hypotheca legal do co-herdeiro, gravado só e só o immovel que 
era commum e que ficou addicto a um só interessado com obrigação de repor, applica-se mutatis mutandis ao caso de uma escriptura dotal, na qual se exarasse individualmente quaes os bens que ficavam assignados á segurança do dote.

Ninguem se nos affronte a dizer que na pratica não tem importancia a argumentação por nós produzida. Não é essa a questão.

O que queremos é que fique patente até á evidencia qual é irrecusavelmente o preceito legal.

Não ha mais nobre dever do jurisconsulto do que cooperar para a verdade consagrada nos textos.

Sabemos perfeitamente que a pratica nem sempre corre de par com a theoria. Sabemos que ha na sociedade, e sempre os houve, homens divorciados do bem e que por meios tortos fazem grande fortuna e assentam em collocação invejavel. Entretanto ha outros que suam a probidade a vida inteira e não conseguem se erguer fóra da chã de uma pobreza apertada.

Quem ha ahi, porém, tão descrido que ouse dizer que as leis sejam preceitos supervacuos ou que as virtudes bem se possam dispensar?!

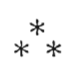

30. Terminemos. A doctrina do Trib. de Maceió é erradissima, mas a do Sr. Cons. Duarte d'Azevedo é calamitosa. Façamos, todos que prezamos seu saber profundo, façamos votos ao céo para que quanto antes, á volta do Imperio, nas refórmas que temos de fazer urgentes no direito civil, sejam seus conselhos um dos mais altos pharoes.

S. Paulo, Setembro de 1898.

Dr. Raphael Correa da Silva 